\title{
Does Fiscal Decentralization Promote Fiscal Discipline?
}

\section{Zafer Akin, Zeynep B. Bulut-Cevik \& Bilin Neyapti}

To cite this article: Zafer Akin, Zeynep B. Bulut-Cevik \& Bilin Neyapti (2016) Does Fiscal Decentralization Promote Fiscal Discipline?, Emerging Markets Finance and Trade, 52:3, 690-705, DOI: 10.1080/1540496X.2015.1012920

To link to this article: https://doi.org/10.1080/1540496X.2015.1012920

曲 Published online: 17 Jul 2015.

Submit your article to this journal

Џll Article views: 158

Q View related articles ๘

View Crossmark data \lceil

4 Citing articles: 2 View citing articles 


\title{
Does Fiscal Decentralization Promote Fiscal Discipline?
}

\author{
Zafer Akin ${ }^{1}$, Zeynep B. Bulut-Cevik ${ }^{2}$, and Bilin Neyapti ${ }^{3}$ \\ ${ }^{1}$ Department of Economics, Ipek University, Ankara, Turkey; ${ }^{2}$ Department of Economics, Middle East \\ Technical University, Ankara, Turkey; ${ }^{3}$ Department of Economics, Bilkent University, Ankara, Turkey
}

\begin{abstract}
We investigate the efficiency and equity implications of a redistributive rule that takes into account both local tax collection efforts and deviation of local incomes from respective targets under alternative fiscal mechanisms. We show that, if the general budget constraint is binding, the proposed transfer rule leads to higher fiscal discipline under fiscal decentralization (FD) than under centralized redistribution. Although the centralized decision yields better income distribution than FD, FD also improves income distribution unambiguously when equalization across regions is targeted explicitly. When localities act strategically, the private sector's utility weight enhances the disciplinary effect of decentralization.
\end{abstract}

KEY WORDS: fiscal decentralization, fiscal discipline, redistribution

\section{Introduction}

Fiscal decentralization (FD) is an institutional mechanism whereby fiscal power and responsibilities are transferred from the central government toward local governments. Following the seminal work of Oates (1972), the literature on FD has been extensive, comprised of both empirical and theoretical studies. A growing literature on the socio-economic consequences of FD has provided mixed evidence on the merits of FD. ${ }^{1}$ Likewise, the recent strand of the empirical literature that investigates the macroeconomic implications of FD is far from reaching a consensus. ${ }^{2}$ Moreover, the effectiveness of FD in attaining the socio-economic objectives has been reported to depend on various structural characteristics and institutional factors. ${ }^{3}$ The current article contributes to this literature by developing an original model to explore the fiscal efficiency and welfare implications of a fiscal institutional design defined by FD and a redistributive rule.

Central government transfers have constituted a major source of financing local fiscal activities. ${ }^{4}$ The need for transfers arises from both vertical and horizontal imbalances, the former of which are common due to greater capacity of central governments in collecting revenue than local governments, while horizontal imbalances arise from the varying fiscal capacities across different regions of a country. Aside from these capacity constraints, inadequate tax collection effort of local governments, a form of moral hazard, also leads to local governments' reliance on central government transfers.

Because local governments benefit from their own spending but not directly from own tax collection effort, inefficiencies may arise when externalities of local government actions are not internalized effectively. In the absence of well-defined rules, favoritism toward political constituencies may also lead to political business cycles, increased fiscal imbalances, macroeconomic instability and inequality. The emphasis on FD in developmental policy agendas has therefore been on the rise, in tandem with the increasingly recognized importance of accountability and transparency in achieving fiscal discipline. ${ }^{5}$ Redistributive rules can improve welfare by reducing or eliminating vertical and horizontal imbalances. If a redistribution mechanism is not well-designed, however, moral hazard and common pool problems may be exacerbated. ${ }^{6}$

Against this background, a couple of recent studies investigate the welfare impact of FD in view of specific redistributive schemes. Sanguinetti and Tomassi (2004) compare the rule-based versus

Address correspondence to Bilin Neyapti, Department of Economics, Bilkent University, 06800 Ankara, Turkey. E-mail: neyapti@bilkent.edu.tr 
discretionary fiscal transfers using a game theoretic framework where transfers are considered as insurance against local shocks across regions under asymmetric information. Welfare comparisons reveal that discretionary financing is more preferable in the event of large local shocks, while rulebased transfers are preferred in case of a high degree of FD that increases the degree of common pool problem. ${ }^{7}$ Stowhase and Traxler (2005) model fiscal competition where costs of tax enforcement are shared across regions where, similar to the current article, tax effort (in their case the rate of auditing local tax collection) becomes local government's strategic tool. Their analysis reveals that the fiscal equalization scheme, based on net revenue sharing, helps to internalize fiscal externalities. The authors concede, however, that the feasibility of the redistributive mechanism they suggest to improve the efficiency in tax collection is questionable in view of informational asymmetries.

$\mathrm{Ma}$ (1997) points out that a redistributive mechanism that takes both efficiency and equity criteria into account is considered to be the most developed one, notwithstanding its information and enforcement costs. $^{8}$ The redistributive mechanism suggested in this article takes this into account and hence differs from that of Stowhase and Traxler (2005) as we also consider the income compensation, or equalization, besides the efficiency aspect. Local income compensation can be viewed either with respect to some pre-defined local targets or some common national target. To measure the degree of fiscal efficiency, or fiscal discipline, we focus on the effectiveness of local governments in collecting local taxes.

This article investigates the fiscal disciplinary implications of such a redistributive rule under alternative fiscal scenarios. Under the scenario of fiscal decentralization (FD), local governments optimally choose their tax collection efforts given a preannounced redistributive rule that both punishes a less-than-full tax-collection effort (measured by the deviation from the revenue collection capacity, or some target revenue) and compensates for the deviation of local incomes from their target. ${ }^{9}$ Two alternative scenarios can be considered under this scheme, depending on the nature of interactions among the local governments. In the first scenario, we consider many small local governments that do not act strategically (denoted simply by FD); while in the second, the number of localities is relatively few and they act strategically, taking into account each others' optimal action (denoted by $\mathrm{FD}^{\mathrm{Nash}}$ ). ${ }^{10}$ Under an alternative scenario, the central government (CG) chooses optimally the level of transfers without a preannounced redistribution rule. ${ }^{11}$

We compare the solutions of the respective problems (FD, FD ${ }^{\mathrm{Nash}}$ and $\mathrm{CG}$ ) for the assessment of the relative effectiveness of the proposed fiscal institutional design, namely fiscal decentralization combined with the redistributive rule. ${ }^{12}$ Due to the complexity of the expressions resulting from the model's solutions, simulations are used to evaluate the results comparatively. The basic model outlined above is rich of extensions. Besides the benchmark case of full information, we analyze the case of asymmetric information when either the poor or the rich region is hit by a shock that local governments observe but the central government does not. In addition, we investigate the effect of incorporating a convergence target into the redistributive rule. Finally, we investigate the implications of both the benchmark and the rest of the scenarios for income distribution for i) fiscal efficiency; ii) welfare; and iii) income distribution.

Simulations reveal that, provided that local governments face a general budget constraint, decentralization leads to greater efficiency, measured by higher tax collection effort and lower size of redistribution, than under centralized decision making. The results remain robust in the case of informational asymmetries between the central and local governments about the local shocks. ${ }^{13}$ When budget constraint is not binding under decentralization, the findings are observed to be reversed however. ${ }^{14}$ This observation is supported by the panel evidence in Neyapti (2013), who shows that both balanced budget and debt rules enhance the negative effect of fiscal decentralization on budget deficit.

In contrast with the pro-decentralization findings of the current model with regard to efficiency, we observe that central decision making dominates decentralized decision making with regard to income distribution. When the target of convergence across localities is considered along with the redistributive rule, however, redistribution under decentralized decision making also improves income distribution unambiguously, although not as much as under centralized decision making. Interestingly, and 
consistent with Bouton et al. (2008), improvements in income distribution under decentralization is inversely related to the size of redistribution.

The rest of the article is organized as follows: In the next section, we present the basic features of the model. The third section reports the redistributive outcomes of different fiscal schemes in a comparative way. We then provide two main extensions to the base-line scenario and evaluate their results. The final section provides the conclusions.

\section{The Model}

The current model focuses on the analysis of public sector behavior in a static framework, taking the decisions of private sector as given. The economy consists of $n$ local governments, redistribution among which is made via the central government. The local governments take policy variables, such as the tax rate $(t)$ set by the central government, as given exogenously. For the sake of simplicity, tax is assumed to be of one type: that on income. The income of each region is assumed to be exogenous. ${ }^{15}$ Taxes are collected by local governments that may exert varying levels of effort in tax collection. ${ }^{16}$ Each local government $i(i=1 \ldots . n)$ thus has an effective tax rate that is given by $t_{i}=t A_{i}$ where $A_{i}$ is the tax collection effort $\left(A_{i} \in[0,1]\right)$. The portion $(1-c)$ of tax revenues is spent by the local government, constituting part of its expenditures $\left(G_{i}\right)$, where $c$ is the proportion sent to the common revenue pool. ${ }^{17}$ In addition, local governments spend what is transferred back to them $\left(T R_{i}\right)$ by the central government according to the announced rule of redistribution. Local government spending is the only form of government spending in a locality. Hence the government spending in region $i$ is given by:

$$
G_{i}=(1-c) t_{i} Y_{i}+T R_{i}
$$

where $Y_{i}$ is the local income, which is commonly observed. For simplicity, localities are assumed to differ only in their income levels that are known ex-ante. Alternatively, localities can be assumed to use the same technology while they differ in their ex-ante known levels of capital and labor. The level of private spending $C_{i}$ is given by: ${ }^{18}$

$$
C_{i}=\left(1-t_{i}\right) Y_{i}
$$

The total size of the transfers $(T R)$ by the central government is equal to the sum of revenues collected in the common pool: $T R=c \Sigma t_{i} Y_{i}$, and other forms of financing do not exist. Given these basic features, the local and central government problems are presented in the next two sections, respectively.

\section{Local Governments' Problem: The Case of Fiscal Decentralization}

Under fiscal decentralization, we consider two alternative scenarios: i) no strategic interaction among the local governments (LGs); ii) the Nash solution, where LGs act strategically but noncooperatively; the two scenarios are denoted by FD and $\mathrm{FD}^{\mathrm{Nash}}$ respectively. The $\mathrm{FD}^{\mathrm{Nash}}$ scheme is relevant for the case of a few or highly polarized LGs, each of which considers that others' decisions affect his or her own welfare significantly. The following sections report the solutions of FD and FD ${ }^{\text {Nash }}$ problems. In both of the schemes, CG preannounces the redistributive rule whose parameters are chosen optimally to correspond to the possible values of local tax collection effort (see Appendix 1); hence the redistributive rule can be viewed as a reaction function.

\section{No Strategic Interaction Among the LGs (FD)}

The process of FD is defined as follows: each local government (LGs) maximizes the utility it obtains from own jurisdiction, subject to the preannounced redistribution rule by the central government. In the case of numerous localities, a common pool problem may arise since each LG internalizes the 
inefficiency from tax collection only partially. Inefficiency in tax collection of a given LG is punished, but nonetheless shrinks the nationwide pool of transfers that may be used for income compensation for all the regions. Noting that nonstrategically acting local governments do not consider the overall budget balance as a constraint, the FD process is likely to result in general budget deficits.

Hence, each LG chooses its level of $A_{i}$, where $0<A_{i} \leq 1$, which stands for the effectiveness in tax collection; this way the $\mathrm{LG}_{\mathrm{i}}$ chooses the effective tax rate for locality $i\left(A_{i} t\right)$. For purposes of tractability, we assume that the local government has a Cobb-Douglass type of utility $\left(U^{L G}\right)$, which is defined over the local private and public consumption: $C_{i}$ and $G_{i}{ }^{19}$ In a log-linear form, $U^{L G}$ of a representative region $i$ is given by:

$$
\underset{A_{i}}{\operatorname{Max}} U^{L G}=\alpha \ln C_{i}+\beta \ln G_{i} \quad ; \text { where } i=1 \ldots n
$$

where $\alpha$ and $\beta$ represent the relative weights of private and government spending in utility; hence they add up to $1 .^{20}$ Given the expressions of $C_{i}$ and $G_{i}$, while increasing $A_{i}$ increases the latter of these terms, it decreases the former due to decreased disposable income.

LG solves the problem in Equation (1), subject to the redistribution rule, given in Equation (2), that accounts for both the efficiency and equity objectives: ${ }^{21}$

$$
T R_{i}=p t Y_{i}\left(A_{i}-1\right)+m\left(Y_{i}^{*}-Y_{i}\right)
$$

where $Y_{i}^{*}$ is an exogenously set target of $Y_{i}{ }^{22} p$ and $m$ are the key institutional parameters that denote the extent to which less than full tax collection effort $\left(A_{i}-1\right)$ is punished ${ }^{23}$ and income deviation from a target is compensated, respectively. These parameters are chosen optimally by the CG (see Appendix 1) given the LG problem's solution. The redistributive rule accounts for both efficiency and equity objectives and, as such, is considered to follow the best practice. ${ }^{24}$

The sequence of the model's solution is as follows:

1. The optimal values of $p$ and $m$ are found by the CG by solving the problem in Appendix 1. CG announces the redistribution rule, which acts like a reaction function corresponding to the stream of $A_{i}$ values.

2. LG solves his own maximization problem by maximizing (1) subject to (2) to find the optimal $A_{i}$.

3. The $p$ and $m$ values corresponding to the optimal $A_{i}$ 's are used to determine the level of $T R_{i}$.

The solution of the LG problem can be written in terms of the optimum effort $\left(A^{0}\right):{ }^{25}$

$$
A_{i}^{o}=\frac{-\alpha m\left(Y_{i}^{*}-Y_{i}\right)+Y_{i}(\beta-\beta c+p(t \alpha+\beta))}{t Y_{i}(\alpha+\beta) *(1-c+p)} .
$$

The amount of total transfers implied by optimal tax effort $A_{i}^{o}$ (see Appendix 3) is found as:

$$
\begin{gathered}
T R=\sum_{i=1}^{n} T R_{i} \text { where } \\
T R_{i}=m(1+\alpha p) Y_{i}^{*}-\frac{(c-1)(m+p t) \alpha+(c-1-p)(m+p(t-1)) \beta}{(c-1-p)(\alpha+\beta)} Y_{i} .
\end{gathered}
$$




\section{Nash Solution to the LG Problem (FD ${ }^{\text {Nash }}$ )}

In case of a small number of LGs, each LG may act strategically, viewing that its transfers result from a common pool of revenues that is partially determined by the efforts of the rest of the LGs. Hence, each LG solves the optimization problem stated in Equations (1) and (2) with an additional constraint: the balanced budget that states that the common pool of revenues is fully redistributed back to them:

$$
T R=c t \sum_{i=1}^{n} A_{i} Y_{i} \quad \text { for } i=1 \ldots n
$$

Given the redistributive rule (2), the optimal level of effort by each $\mathrm{LG}_{i}$ thus become dependent on others' optimal efforts (where $j=1 \ldots n$, and $i \neq j$ ):

$$
T R_{i}=T R-\sum_{j \neq i}^{n} T R_{j}=c t \sum_{i=1}^{n} A_{i} Y_{i}-\sum_{j \neq i}^{n}\left[p t Y_{j}\left(A_{j}-1\right)+m\left(Y_{j}^{*}-Y_{j}\right)\right]
$$

The sequence of the model solution for $\mathrm{FD}^{\text {Nash }}$ only differs from FD in step 2, which becomes (2): LG acts strategically and chooses his tax effort by maximizing (1) subject to Equations (2) and (5). Since Equations (2) and (5) are contained in Equation (6), the $\mathrm{FD}^{\mathrm{Nash}}$ problem is defined as the maximization of Equation (1) subject to Equation (6). The solution yields $L G_{\mathrm{i}}$ 's reaction function:

$$
A_{i}^{o}=\frac{(p-c) \alpha t A_{j} Y_{j}+\beta Y_{i}-\alpha p t Y_{j}+m \alpha\left(Y_{j}^{*}-Y_{j}\right)}{(\beta+\alpha) t Y_{i}} .
$$

Since each region acts in the same manner, the Nash equilibrium for $A_{i}^{o}(i=1,2)^{26}$ is given by (Appendix 2):

$$
A_{i}^{o-N a s h}=\frac{((p-c) \alpha)\left(\beta Y_{j}-\alpha p t Y_{i}+m \alpha\left(Y_{i}^{*}-Y_{i}\right)\right)+(\alpha+\beta)\left(\beta Y_{i}-\alpha p t Y_{j}+m \alpha\left(Y_{j}^{*}-Y_{j}\right)\right)}{\left((\beta+\alpha)^{2}-((p-c) \alpha)^{2}\right) t Y_{i}} .
$$

\section{The Central Government's Problem}

As alternative to the FD problem, the central government $(\mathrm{CG})$ is assumed to choose optimally the level of transfers by maximizing the overall welfare $\left(\mathrm{U}^{\mathrm{CG}}\right)$; in the context of the current problem, welfare is the sum of the utilities of all localities. CG is assumed to take LGs' efforts $\left(A_{i}\right.$ 's) given. ${ }^{27}$ The main constraint is that total transfers are equal to the common pool of revenues, as it is in the case of $\mathrm{FD}^{\text {Nash }}$. Hence CG solves:

$$
\underset{T R_{i}}{\operatorname{Max}} U^{C G}=\sum_{i=1}^{n}\left[\alpha \ln C_{i}+\beta \ln G_{i}\right]
$$

subject to Equation (5). The solution yields (see Appendix 3):

$$
T R_{i}=(t / n) \sum_{i=1}^{n}\left(A_{i} Y_{i}\right)-(1-c) t A_{i} Y_{i}
$$


which states trivially that the optimum redistribution implies equal local government spending in each locality $\left(G_{i}=(1-c) t A_{i} Y_{i}+T R_{i}\right){ }^{28}$ This result is consistent with the standard assumption of policy uniformity under centralization.

\section{Implications}

In order to derive the policy implications regarding the three fiscal schemes outlined above, we perform comparative static analysis. The signs of the partial derivatives that are observed explicitly are all in the expected directions: in the case of CG's optimization, $c, t, A_{i}$ and $Y_{\mathrm{i}}$ all have positive effects on total transfers. Under FD, the effect of the deviation of income from target on $A_{i}$ and $T R_{i}$ are negative and positive, respectively. In addition, in the $\mathrm{FD}^{\mathrm{Nash}}$ problem, efforts of localities are positively correlated. Due to the complexity of the expressions, explicit signs for the rest of the partial derivatives could not be obtained, however. We therefore perform a simulation analysis in order to obtain the signs of the remaining partials, using a set of feasible values for the model parameters and calibrating the variables. The results of all the comparative-statics, those that are explicit and those that are obtained based on the simulations, are reported in Appendix 3 and Table A1. The simulations also allow us to obtain the rankings of the alternative FD and the CG problems with regard to fiscal efficiency.

The following are the range of values for the model parameters ${ }^{29}$ as well as for the exogenously given values of $Y_{i}$ and $Y_{i}^{*}$. For tractability, we assume that there are two $\mathrm{LG}_{i}$ 's $(i=1,2)$ the first of which is poor region and the second is rich. The assumption of two local governments is kept through all scenarios below:

$$
\begin{aligned}
& \alpha=0.7 ; \beta=0.3 ; c=0.1 ; t \epsilon[0.1 ; 0.5] ; A_{i} \epsilon(0 ; 1] ; \\
& Y_{1} \epsilon[100 ; 500] ; Y_{1}{ }^{*} \epsilon\left[(1.01) Y_{1} ;(1.1) Y_{1}\right] ; \\
& Y_{2} \epsilon[1,000 ; 30,000] ; Y_{2}{ }^{*} \epsilon\left[(1.01) Y_{2} ;(1.1) Y_{2}\right] .
\end{aligned}
$$

The selections of the ranges of values for $\alpha$ and $\beta$ can be justified on the grounds of the relative shares of state and private sectors, respectively. $c$ is chosen to be 0.1 to account for the case of high degree of revenue decentralization. Simulations also take into account the constraint that the total of targeted level of aggregate output exceeds the total of its actual level. ${ }^{30}$ The policy parameters $p$ and $m$ are obtained as the optimal solutions to an alternative CG problem reported in Appendix 1, where CG chooses them to maximize the aggregate utility given the general budget constraint. Recalling that LGs optimally select their tax effort given the redistributive rule, simulations are performed by matching the optimal $A_{i}$ 's of the LG problem with the feed values that are used to calculate the optimal set of $p$ and $m$ pairs. ${ }^{31}$ As a result, the optimal $A_{i}$ pairs for the two localities, and the implied $T R_{i}$ 's, are simulated (using Matlab) for the FD and $\mathrm{FD}^{\text {Nash }}$ procedures. The resulting simulation data that are comprised of the optimal $p$ and $m$ pairs, which correspond to the matching optimal and feed $A_{i}$ 's and range between 0 and 1 , are 19355 and 5507 for the FD and $\mathrm{FD}^{\text {Nash }}$ procedures, respectively. ${ }^{32}$

In order to compare the level of transfers across the three fiscal regimes for each optimal $p$ and $m$ pairs, we use the same set of optimal $A_{i}$ pairs to calculate the optimal $T R_{i}$ 's for the CG problem. Next, to compare the implied levels of fiscal discipline measured by the effort level under the FD and CG procedures, we take the optimal $T R_{i}$ 's simulated for the two alternative FD regimes and find the implied sum of $A_{i}$ 's under the CG regime.

Based on the signs of the partial derivatives reported in Table A1, the following remarks can be made. Under $\mathrm{FD}^{\text {Nash }}$, an increase in the tax rate $(t)$ leads to an increased competition among the LGs over a greater size of redistribution (to compensate for the lower utility derived from private consumption), which has a positive effect on the level of tax effort. In this case, the redistribution rule seems to generate incentives compatible with the main fiscal policy instrument, $t$, as the 
downward portion of the Laffer curve seems to be eliminated. Under FD, however, the effect of $t$ on the tax effort is indeterminate.

Increasing the central government's share in local tax revenues $(c)$ also leads to greater tax effort and transfers under $\mathrm{FD}^{\mathrm{Nash}}$ because expectation of a greater common pool leads each LG to increase its tax effort. The reverse occurs under FD, however, where an increase in $c$ implies lower tax effort and transfers; when LGs behave nonstrategically, they try to compensate for the utility loss arising from a decrease in $G_{i}$, which decreases in $c$, by increasing the utility from private consumption that is negatively related with the effort level.

Remark 1: Both increasing the tax rate $(t)$ and the extent of centralization of the tax revenues $(c)$ leads to an increase in fiscal discipline and the size of transfers under $\mathrm{FD}^{\mathrm{Nash}}$.

The higher the weight on public consumption in the utility function $(\beta)$ the lower is the tax effort and redistribution under $\mathrm{FD}^{\mathrm{Nash}}$. This is because local governments can afford to forego some transfers via increased punishment in return of additional utility received from private consumption, which is negatively related to the optimal tax effort. This result arises since each LG acts in consideration of a smaller common pool of revenues given that $\left(\partial A_{i} / \partial A_{j}\right)>0 .{ }^{33}$ When LGs do not act strategically, however, this effect is not observed: an increase in $\beta$ leads to increased effort in order to generate more spending for themselves, which also results in a larger common pool.

The higher the weight on private spending in the utility function $(\alpha)$, the higher is the tax effort under FD ${ }^{\text {Nash }}$, which negatively affects the after tax income that in turn leads to lower private spending. This seemingly counterintuitive result can be explained by the income effect of an increase in $\alpha$ exceeding the substitution effect. Income effect arises from increasing the effort, because LG can obtain the same utility with a lower private income than before. Meanwhile, the increase in the effort increases LG's utility through the public spending channel as transfers increase due to reduced punishment. Substitution effect, on the other hand, leads to a decrease in the LG's effort so as to increase private consumption in order to take advantage of its increased weight in utility. This complementarity between the size of the private sector and increased fiscal discipline under FD can be viewed as a challenge to Tanzi (2000) who argues FD to be a substitute for privatization. In case of FD without strategic behavior, the effects of $\alpha$ on both tax effort and transfers are indeterminate.

Remark 2: When local governments act strategically, the proposed redistributive mechanism leads to greater fiscal discipline under fiscal decentralization, the greater the weight of private spending in the economy.

The positive effect of the punishment parameter $(p)$ has the expected positive effect on the level of effort under both $\mathrm{FD}$ and $\mathrm{FD}^{\mathrm{Nash}}$. Transfers to the poor region are similarly affected under FD, although the effect of $p$ on transfers is indeterminate under $\mathrm{FD}^{\mathrm{Nash}}$. The effect of the income compensation parameter $(m)$ on tax effort is negative under both FD and $\mathrm{FD}^{\mathrm{Nash}}$. Hence, only the punishment component of the redistributive mechanism works as a fiscal disciplining device, not the income compensation component. In addition, while the sum of transfers decreases in $m$ under $\mathrm{FD}^{\mathrm{Nash}}$, it increases in $m$ under FD; that is, the loss in tax collection efficiency is not sufficient to offset the size of redistribution under FD. Model simulations indicate that, on average, the punishment of fiscal imprudence accounts for about 40 percent of the equalization transfers. ${ }^{34}$ Under FD ${ }^{\text {Nash }}$, however, the budget is balanced given the way the problem is set up.

Proposition: Under FD, income compensation, or the deviation of income from the target, reduces the incentive for tax collection (moral hazard).

Proof: Given $\frac{\partial A}{\partial m}=\frac{-\alpha\left(Y_{i}^{*}-Y_{i}\right)}{t Y_{i}(1-c+p)}$, because $\alpha>0 ; Y_{i}^{*}>Y_{i}$; and $c<0.1$, this sign of the partial is negative.

Remark 3: Income compensation causes moral hazard under $\mathrm{FD}^{\mathrm{Nash}}$ as well.

To investigate the fiscal disciplinary effects of the alternative fiscal schemes, we next compare the implied level of total tax efforts and size of transfers. Based on a common set of values of $p$ and $m$, 
which corresponds to the same set of $A_{i}$ 's for the $\mathrm{FD}^{\text {Nash }}$ and $\mathrm{CG}$ models, ${ }^{35}$ simulations yield the following ordering for total levels of effort and redistribution for the case of nonpositive budget deficits $^{36}$ :

$$
\begin{gathered}
\sum_{i} A_{i}^{F D}>\sum_{i} A_{i}^{F D-N a s h}\left(=\sum_{i} A_{i}^{C G}\right) \\
\sum_{i} T R_{i}^{F D}<\sum_{i} T R_{i}^{F D-N a s h}\left(=\sum_{i} T R_{i}^{C G}\right) .
\end{gathered}
$$

These results indicate that FD leads to larger total tax effort and smaller size of redistribution than CG, and under $\mathrm{FD}^{\mathrm{Nash}}$, where LGs face a balanced budget constraint (Equation 5). The results are reversed, however, in case budget deficits are allowed under FD. This is a straightforward implication of the common pool problem: FD reduces fiscal discipline when externalities are not internalized fully; hence, FD $^{\text {Nash }}$ yields higher fiscal discipline than FD when general government budget deficits are allowed. In case a general budget constraint is not imposed, both the size of redistribution is greater and tax effort is lower under FD than under $\mathrm{FD}^{\mathrm{Nash}}$ (and CG). This result is one of the main contributions of the current formal framework to the literature.

Remark 4: When a general budget constraint is imposed, FD leads to greater fiscal discipline than both $\mathrm{FD}^{\text {Nash }}$ and $\mathrm{CG}$ in terms of higher tax collection effort.

Hence, given the above redistributive rule, centralization (CG) is not the first best if budget constraint is imposed effectively. Although evidence on the implementation of the above type of redistribute rule is too rare to carry out an empirical test of these findings, recent evidence on the significant role of balanced budget rules on the fiscal disciplinary effect of FD provides strong support for this result (see, Neyapti 2013).

\section{Extensions}

This section investigates two extensions of the above benchmark scenario of full information. The first part reports the effects of choosing equal income targets across localities in the redistributive rule. The second part reports the effects of local income shocks that the CG observes indirectly, through the remitted revenues. The third part reports the equity impact of redistribution under all fiscal scenarios and informational assumptions.

\section{Equalization of Incomes Across Localities}

Eliminating horizontal imbalances is one of the main objectives of redistribution. Hence, this section focuses the implications of the FD, $\mathrm{FD}^{\mathrm{Nash}}$, and $\mathrm{CG}$ schemes in case target incomes of different localities are chosen to be the same. This extension also addresses the question of whether the above results are an artifact of a particular set of income levels.

To examine this case, we choose the levels of incomes to be closer in range and income targets across localities to be the same:

$$
t \epsilon[0.1 ; 0.5] ; Y_{1} \epsilon[100 ; 1,000] ; Y_{2} \epsilon[2,000 ; 10,000] ; Y_{i}^{*} \epsilon\left[(1.01) Y_{2} ;(1.1) Y_{2}\right] .
$$

The corresponding set of (positive) $p$ and $m$ values that produce feasible data points $\left(A_{i}\right.$ values ranging between zero and one) are 39030 for the case of FD. As noted earlier, these set of simulations also indicate greater total tax effort (and smaller size of redistribution) under FD as compared to the CG problem, when the LGs face the general budget constraint. As in the former case, FD $^{\text {Nash }}$ and CG problems produce the same set outcomes due to the common budget-balance constraint, implying that the strategic behavior of local governments competing for a common pool produces inferior fiscal 
results (in terms of discipline), as compared to nonstrategic ones, in case the concern for equity is integrated into fiscal policy.

Comparative statics of the both CG and FD problems based on the above range of parameter values differ from the formerly reported ones in the following ways. First, the former ambiguous effects of both $t$ and $\alpha$ on both the level of tax effort and the size of transfers turn negative. This indicates that when the redistributive rule is adopted along with an equalization target, increasing taxes have a negative effect on fiscal discipline under FD, as viewed on the right side of the Laffer curve. Second, $p$ has a negative effect on $T R$ in case of FD. These results are in contrast with the findings under $\mathrm{FD}^{\mathrm{Nash}}$, the results for which are the same as for $\mathrm{CG}$ due to the common budget constraint. The rest of the comparative statics yields the same signs as before, which reinforces the validity of our findings. Hence,

Remark 5: Adoption of an equalization target along with the proposed redistributive rule renders tax increases an ineffective tool of fiscal discipline.

In a study of German fiscal system, Von Hagen and Hepp (2000) suggest that equalization across localities leads to adverse incentives for tax collection. Under the equalization target, our model provides support for the Von Hagen and Hepp argument the higher the utility weight on the private spending. Our findings indicate that the adoption of the fiscal rule proposed in this article may also lead to such adverse incentives provided that budget constraint is not binding.

\section{Shocks and Asymmetric Information}

So far, the model assumed that there is no uncertainty regarding the realizations of local incomes. To make the model more realistic, we consider a case where idiosyncratic shocks hitting local economies are observed perfectly by the local governments, but not by the central government. This conforms with the basic philosophy of decentralization since, as Sanguinetti and Tomassi state, "... the whole debate over the virtues of decentralization would be a non-issue if asymmetric information was not important, since in that case a centralized system would dominate all alternative arrangements" (153).

CG receives the portion of local taxes: $\left[\left(\operatorname{ctA}_{i} Y_{i}\right)\left(1+\varepsilon_{i}\right)\right]$ without observing the level of the shock: $\varepsilon_{i}$. Hence, $C G$ is not able to distinguish whether the change in the tax collection is due to a change in the local tax effort or to a shock to the income level, hence it follows the LG's report of $Y_{i}$ and $A_{i}$, which may diverge from the actualization of those variables. ${ }^{37}$ Considering that $\left(1+\varepsilon_{i}\right)$ may originate from either one, $\mathrm{CG}$ uses the following redistributive rule:

$$
T R_{i}=p\left[t Y_{i} \sqrt{1+\varepsilon_{i}}\left(A_{i} \sqrt{1+\varepsilon_{i}}-1\right)\right]+m\left(Y_{i}^{*}-Y_{i} \sqrt{1+\varepsilon_{i}}\right) .
$$

While each LG observes its own shock, it also conjectures that the CG will apply the above redistributive rule. As a result of this asymmetry, despite the fact that both CG and FD ${ }^{\text {Nash }}$ face the budget constraint ${ }^{38}$, transfers and the implied effort levels differ between these two fiscal schemes also, which is contrary to the former set up where all governments had full information.

Simulations of the model are carried out assuming that the shock term follows a normal distribution. Separate simulations are performed for the set of positive and negative shocks that are both of the magnitude of within 50 percent of the income level, that is $\varepsilon_{1} \in(-0.5 ; 0.5) Y_{1}$. The positive or negative shocks may hit either the poor or rich localities, under which the results do not differ. One may consider, however, that shocks to the poor locality are more likely to occur since poor regions are more often than not associated with the traditional sector that is prone to weather conditions. $^{39}$

Simulations reveal that both FD and $\mathrm{FD}^{\mathrm{Nash}}$ generate better outcomes than CG under asymmetric shocks. ${ }^{40}$ These findings can be summarized as follows: 


$$
\begin{gathered}
\sum_{i} A_{i}^{F D}>\sum_{i} A_{i}^{C G} ; \text { and } \sum_{i} A_{i}^{F D-N a s h}>\sum_{i} A_{i}^{C G} \\
\sum_{i} T R_{i}^{F D}<\sum_{i} T R_{i}^{F D-N a s h} ; \text { and } \sum_{i} T R_{i}^{F D-N a s h}<\sum_{i} T R_{i}^{C G} .
\end{gathered}
$$

These findings are robust across the sign of the shocks and the size of locality; introduction of the equal income targets (convergence) also does not affect the result. The results confirm the findings obtained under the assumption of no shocks, with the additional information regarding the case of $\mathrm{FD}^{\mathrm{Nash}}$ that can now be obtained as distinct from the case of CG.

\section{Income Distribution Effects of Transfers: Alternative Fiscal Schemes}

To evaluate the income distribution effects of the alternative fiscal schemes, we compare the pretransfer income ratios of the localities with those after redistribution takes place. When $\left(Y_{1} / Y_{2}\right) /\left[\left(Y_{1}\right.\right.$ $\left.\left.+T R_{1}\right) /\left(Y_{2}+T R_{2}\right)\right]$ is less than 1 (given that locality 1 is the lower income locality), redistribution is said to improve income distribution.

Simulations indicate that CG problem always yields better income distribution than the two FD regimes (except under full information where $\mathrm{CG}$ and $\mathrm{FD}^{\mathrm{Nash}}$ are not distinguished from each other). Moreover, it is observed that income distribution may even worsen under FD or FD ${ }^{\text {Nash }}$ unless the equalization objective is imposed via equal income target ranges in the redistributive rule. Under the equalization scenario, however, even though income distribution improves under all the fiscal scenarios, centralized redistribution leads to greater equality than both of the FD regimes. Hence, the proposed redistributive rule works as an insurance against local shocks - by not-worsening income distribution in case of a negative shock, only when the rule is combined with the objective of equalization (or convergence) across localities.

Remark 6: Welfare gains vary under alternative fiscal institutional schemes: while CG delivers higher equity than FD (and $\mathrm{FD}^{\mathrm{Nash}}$ ), FD is superior with regard to the efficiency criterion if budget constraint is binding. In the absence of balanced budget, decentralization leads to welfare losses (both in terms of efficiency and equity).

Bouton et al. (2008) demonstrate theoretically and empirically that income distribution under FD worsens in vertical imbalances, or the size of transfers. Our findings show, however, that when the redistributive rule involves the target of convergence among local incomes, redistribution under both $\mathrm{FD}$ and $\mathrm{FD}^{\mathrm{Nash}}$ improves income distribution, though not as much as under $\mathrm{CG}$, while $\mathrm{CG}$ has a greater size of transfers.

\section{Conclusions}

This article presents a model to analyze the efficiency and equity implications of fiscal decentralization. Fiscal decentralization is defined as the local governments' decision on their tax collection effort given the redistributive rule announced and implemented by the central government. Local governments may or may not act strategically, providing two alternative scenarios of fiscal decentralization. The transfer mechanism entails both income compensation and punishment of insufficient tax collection effort.

The main policy implications of the proposed fiscal institutional design are that:

i. FD has a fiscal disciplining effect because, when the budget constraint is binding, it yields greater efficiency (both higher total tax collection effort and lower size of redistribution) than in the case of the CG problem; when local governments do not face a budget constraint, however, $\mathrm{CG}$ is more efficient.

ii. The extent of privatization of the economy improves the fiscal disciplining role of FD only when local governments act strategically $\left(\mathrm{FD}^{\mathrm{Nash}}\right)$. 
iii. Redistribution under CG leads to better income distribution than both FD and FD ${ }^{\text {Nash }}$, indicating a trade-off between the objectives of efficiency and equity. Furthermore, an increase in the tax rate is observed to increase both the size of transfers and the level of tax effort in case of FD $^{\mathrm{Nash}}$.

A dynamic extension of the current model explores the capital accumulation and welfare implications under FD facing the redistributive rule presented here (Bulut-Cevik and Neyapti 2014). Taking the balanced budget constraint binding, the authors show that FD is associated with higher steady-state level of fiscal efficiency the larger the parameters of the redistributive rule, which is consistent with the findings of the static model.

\section{Notes}

1. See, for example, Bardhan and Mookherjee (1998), Panizza (1999), Barrett (2000), Blanchard and Shleifer (2000), Dethier (2000), Hope (2000), Lin and Liu (2000), Norris et al. (2000), de Mello (2000 and 2004), Tanzi (2000), Treisman (2000), Von Braun and Grote (2000), Eaton (2001), de Mello and Barenstein (2001), Wasylenko (2001), Feltenstein and Iwata (2002), and Fisman and Gatti (2002). A review of those findings may be found in Neyapti (2010), among others.

2. Davoodi and Zou (1998) report a negative relationship between FD and growth in less developed countries; Martinez-Vazquez and McNab (2006) show a mixed evidence on this relationship and Thiessen (2003) argues that only moderate FD leads to growth. By contast, Jalil et al. (2014) suggest a strong statistically significant positive relation between FD and economic growth in most provinces in China. King and Ma (2001) and Neyapti (2004) both show a negative relationship between revenue decentralization and inflation. Jin and Zou (2002) show that government size is positively related with expenditure decentralization and negatively related with revenue decentralization. Neyapti (2006) shows that revenue decentralization leads to better income distribution the higher is governance. Kappeler and Välilä (2008) argue that FD boosts public investment productivity. Neyapti (2010) shows that FD is significantly associated with lower budget deficits in largely populated countries.

3. See, for example, Oates (1999); de Mello (2000); Tanzi (2000); Drummond and Masor (2003); Smoke et al. (2006); Bouton et al. (2008); and Neyapti (2004, 2006, 2010).

4. Central governments have both wider available tax bases and better tax collection capacity than local governments. Although many developed countries have relatively low vertical imbalances, central government transfers still constitute 50 percent to 70 percent of local government budgets. In countries like Peru, Portugal and Iran this ratio has been more than 90 percent.

5. See IMF 2009 for a recent survey of the experience with fiscal rules around the world. Neyapti (2013) demonstrates empirically that fiscal disciplinary effects of fiscal decentralization and rules reinforces each other.

6. Unlike the existing studies, the problem addressed in the current framework is not one of optimal taxation, which emphasizes equalization of marginal cost of taxation across different tax sources. Boadway et al. (2003), for example, examine the relationship between FD and equalization via redistribution in optimal taxation framework, with a focus on migration across regions.

7. Sanguinetti and Tomassi (2004) is not directly comparable to the current one as the current article considers a redistributive rule and the former considers that taxes are set by both local and federal governments.

8. Ma (1997) reports four classifications of fiscal transfer systems that focus on either efficiency or equity objectives or both. In the first, transfers are made on the basis of both equalization of fiscal capacities and expenditure needs across regions. The second method only considers equalization of fiscal capacities; the third only considers equalizing expenditure needs, measured by a weighted average of various socioeconomic and demographic indicators. A final classification of fiscal transfer methods entails the equalization of transfers only on the per capita basis.

9. CG announces the redistributive rule, and decides the level of rule parameters optimally. One may consider punishment as a second type of tax that the central government imposes on local governments.

10. We do not consider a case of collusion among the localities which would, in the limit, collapse to the problem of central government.

11. Boadway et al. (2003) and Stowhase and Traxler (2005) also compare central and local government decision making.

12. Both Boadway et al. (2003) and Stowhase and Traxler (2005) similarly compare central and local government decision making.

13. In the absence of informational asymmetries, simulations do not allow a ranking between the $\mathrm{FD}^{\mathrm{Nash}}$ and CG problems with respect to the total effort and the size of redistribution. 
14. Modifying the current model to explicitly incorporate the burden of spending in the FD problem is an interesting extension, although it adds further the current complexity of the model and makes the solution intractable. The punishment component of the redistributive rule employed here serves similar purpose, however.

15. We assume that only the levels of productive factors vary across regions. A natural extension of this model is to introduce heterogeneity across regions in terms of the relative endowments sizes, suggesting different types of production across regions.

16. While income-tax is generally centrally collected, unless perhaps in federal systems, the local government's optimization of tax collection effort can be justified on a couple of grounds: first, by helping monitor the economic activity subject to tax collection, local governments can be rewarded via some preannounced incentive mechanisms, as this model proposes. Second, local government's effort to collect income tax limits unrecorded economic activity and tax evasion, which helps improve local tax collection efficiency in general.

17. Aslim and Neyapti (2013) analyze endogenous determination of FD, which is beyond the scope of the current study.

18. For the economy as a whole, total transfers are equal to common pool of revenues, leading one to obtain: $\Sigma Y_{i}=\Sigma\left(C_{i}+G_{i}\right)$. For a given locality, $C_{i}+G_{i}=Y_{i}+$ "net transfers," where "net transfers" are given by $\left(T R_{i}-c t_{i} Y_{i}\right)$.

19. The assumed concavity of the utility function is to satisfy the necessary condition for the existence of a solution; sufficiency conditions are also met.

20. This formulation allows for a large spectrum of the degree of benevolence for local governments, indicated by relative weights.

21. Boadway and Shah (2007) define the first part of this expression as deviation from average effort; for purposes of model tractability, we instead compare local effort with full tax collection capacity. Boadway and Shah (2007) note that implementation of these rules is prone to various inefficiencies even in developed countries.

22. $Y_{i}^{*}$ may be some fixed growth rate over the previous realization of $Y_{i}$. Simulations are run assuming that $Y_{i}$ $\leq Y_{i}^{*}$. In one of the extensions provided below, $Y_{i}^{*}$ 's will be taken to be the same across localities.

23. To measure the target level of tax collection, regions with similar income levels can be taken into account to calculate a benchmark level of tax revenue.

24. See also Ma (1997).

25. The game between CG and LGs is similar to the leader-follower type game and the game among the LGs is similar to the simultaneous quantity (Cournot) competition game. The simulations are conducted such that the interaction between LGs and the CG is achieved by matching the optimal $A_{i}$ 's resulting from the LG problem with those used as the feed values in the redistributive rule of the CG.

26. Throughout the article $n=2$ is assumed for simplicity.

27. As standard in simultaneous game analyses, we compare the optimal solutions of the CG with those of FD or $\mathrm{FD}^{\text {Nash }}$. Hence, we use the values of $A_{i}$ 's that are optimally selected ones under the LG problem across both fiscal schemes. Likewise, the same set of $T R$ s is used to compare the implied effort levels for case of CG with those of FD or $\mathrm{FD}^{\text {Nash }}$.

28. It is common that CGs use the common pool toward meeting their own constituencies' demands and for political survival rather than for improving income distribution. Given the already complex nature of the problem at hand, however, we refrain from political economy aspects of redistribution.

29. Based on the marginal income and effective (labor and capital) tax calculations of Easterly and Rebelo (1993), Mendoza et al. (1994), and Wolff (2005), the tax rate can be considered to be $0.1<t<0.5$.

30. The income levels can be considered to be in per capita dollar terms.

31. Note that the optimal $p$ and $m$ are chosen for a range of feed values of $A_{i}$ (see Appendix 1).

32. The procedure to obtain the simulation data is as follows. First, for the set of feasible $A_{1}, A_{2}, Y_{1}$ and $Y_{2}$ values, the corresponding optimal $p$ and $m$ values are calculated from the CG problem. Then, the level of optimal tax effort is calculated (simulated for the feasible ranges of the rest of the parameter values in the model) in the LG problem. For the purpose of comparison, we then select the matching sets of optimal and feed $A 1_{o}$ and $A 2_{0}$ values found in the LG and the CG problems. In the matching process, the difference between optimal and calculated tax effort is limited by a tolerance number.

33. The condition is $p>c$, which is met in the simulations. While increasing own tax collection effort increases the transfers received by a region, increased tax collection effort of the other region leads to reduced transfers.

34. This can be compared to the Robin Hood tax reported in Shah (in Boadway and Shah 2007): in Switzerland 41 percent of the financing of equalization comes from the rich.

35. The equality between $\mathrm{FD}^{\mathrm{Nash}}$ and $\mathrm{CG}$ arises from the fact that the budget constraint is common in the two problems.

36. A sample of simulations can be requested from the authors.

37. This is unlike the full or no insurance cases in Sanguinetti and Tomassi (2004).

38. Besfamille and Lockwood (2008) argue that the efficiency gains (in terms of higher effort) obtained through hard budget constraints under FD may be counter balanced by the efficiency losses in terms of underinvestment. 
39. When the shock hits the poor locality, the usable number of observations obtained for the FD and FD ${ }^{\text {Nash }}$ problems are 2215 and 6683 for the case of positive shock, and 26733 and 33821 for the case of negative shock, respectively. Under the scenario of equalization, the respective data points are $39030,27158,38891$, and 4261 .

40. Because the source of shocks is not directly observed by the government, the optimal choices of the CG and $\mathrm{FD}^{\mathrm{Nash}}$ are different from each other.

\section{Acknowledgments}

We are grateful for the financial and academic support provided by the Scientific and Technological Research Council of Turkey (TUBITAK). We thank the participants at the workshop at Bilkent University and the seminars at Koc University, Bosphorous University, TOBB-ETU, METU, and the University of Southern California, with special thanks to Cagri Saglam for his valuable remarks on the model's set-up. Last, but not least, we deeply appreciate the contributions of Nida Cakir on the earlier version; Tunahan Kokmen also provided valuable research assistance on an initial version.

\section{References}

Aslim, G., and B. Neyapti. 2013. "Welfare Effects of Fiscal Decentralization: A Political Economy Approach." Unpublished manuscript. Ankara, Turkey: Bilkent University.

Bardhan, P., and D. Mookherjee. 1998. "Expenditure Decentralization and the Delivery of Public Services in Developing Countries." Working Paper no. C98-104, Center for International and Development Economics Research, Berkeley, California.

Barrett, B.F.D. 2000. "Decentralization in Japan: Negotiating the Transfer Authority." Japanese Studies 20, no. 1: 33-48.

Besfamille, M., and B. Lockwood. 2008. "Bailouts in Federations: Is a Hard Budget Constraint Always Best?" International Economic Review 49, no. 2: 577-593.

Blanchard, O., and A. Shleifer. 2000. "Federalism with and Without Political Centralization: China Versus Russia." Working Paper no. 7616, NBER, Cambridge, MA.

Boadway, R.; K. Cuff; and M. Marchand. 2003. "Equalization and the Decentralization of Revenue- Raising in a Federation." Journal of Public Economic Theory 5, no. 2: 201-228.

Boadway, R.W., and A. Shah. (Eds.). 2007. Intergovernmental Fiscal Transfers: Principles and Practices. Washington, DC: World Bank Publications.

Bouton, L.; M. Gassner; and V. Verardi. 2008. "Redistributing Income Under Fiscal Vertical Imbalance.” European Journal of Political Economy 24, no. 2: 317-328.

Bulut-Cevik, Z. B., and B. Neyapti. 2014. "Fiscal Efficiency, Redistribution and Welfare." Economic Modelling 41, issue C: $375-382$.

Davoodi, H. R., and H. Zou. 1998. "Fiscal Decentralization and Economic Growth: A Cross-Country Study." Journal of Urban Economics 43, no. 2: 244-257.

De Mello, L. 2000. "Fiscal Decentralization and Intergovernmental Fiscal Relations: A Cross-Country Analysis." World Development 28, no. 2: 365-380.

. 2004. "Can Fiscal Decentralization Strengthen Social Capital?” Public Finance Review 32, no. 1: 4-35.

De Mello, L., and Barenstein, M. 2001. "Fiscal Decentralization and Governance: A Cross-Country Analysis," IMF Working Paper no. WP/01/71.

Dethier, J.J. (Ed.). 2000. Governance, decentralization, and reform in China, India, and Russia. Boston, MA: Kluwer Academic Publishers.

Drummond, P., and A. Mansoor. 2003. "Macroeconomic Management and the Devolution of Fiscal Powers." Emerging Markets, Finance and Trade 39 no. 1: 63-85

Eaton, K. 2001. "Political Obstacles to Decentralization: Evidence from Argentina and Philippines." Development and Change 32, no. 1: 101-127.

Easterly, W., and S. Rebelo. 1993. "Marginal Income Taxes and Economic Growth in Developing Countries." European Economic Review 37, nos. 2-3: 409-417.

Feltenstein, A., and S. Iwata. 2002. "Decentralization and Macroeconomic Performance in China: Regional Autonomy Has Its Costs." Journal of Development Economics 76, no. 2: 481-501.

Fisman, R., and R. Gatti. 2002. "Decentralization and Corruption: Evidence Across Countries.” Journal of Public Economics 83, no. 3: $325-545$.

Hope, K.R. 2000. "Decentralization and Local Governance Theory and Practice in Botswana." Development Southern Africa 17, no. 4: 519-534.

International Monetary Fund. 2009. "Fiscal Rules: Anchoring Expectations for Sustainable Public Finances." SM/09/274, prepared by the Fiscal Affairs Department, Washington, DC.

Jalil, A.; M. Feridun; and B.L. Sawhney, 2014. "Growth Effects of Fiscal Decentralization: Empirical Evidence from China's Provinces." Emerging Markets Finance and Trade 50, no. 4: 176-195

Jin, J., and H. Zou. 2002. "How Does Fiscal Decentralization Affect Aggregate, National and Subnational Government Size?" Journal of Urban Economics 52, no. 2: 270-293. 
Kappeler, A., and T. Välilä. 2008. "Fiscal Federalism and the Composition of Public Investment in Europe." European Journal of Political Economy 24, no. 3: 562-570.

King, D., and Y. Ma. 2001. "Fiscal Decentralization, Central Bank Independence and Inflation.” Economic Letters 72, no. 1: 95-98.

Lin, J.Y., and Z. Liu. 2000. "Fiscal Decentralization and Economic Growth in China.” Mimeograph. Chicago, IL: University of Chicago.

Ma, J. 1997. "Intergovernmental Fiscal Transfer: A Comparison of Nine Countries.” Working Paper Series no. 1822, World Bank Economic Development Institute, The World Bank.

Martinez-Vazquez, J., and R. M. McNab. 2006. "Fiscal Decentralization, Macrostability and Growth." Hacienda Pública Española/Revista de Economía Pública 179, no. 4: 25-49.

Mendoza, E.; A. Razin; and L.L. Tesar. 1994. "Effective Tax Rates in Macroeconomics: Cross Country Estimates of Tax Rates on Factor Incomes and Consumption." Journal of Monetary Economics 34, no. 3: 297-323.

Neyapti, B. 2004. "Fiscal Decentralization, Central Bank Independence and Inflation.” Economics Letters 82, no. 2: $227-230$. . 2006. "Revenue Decentralization and Income Distribution." Economics Letters 92, no. 3: 409-416.

2010. "Fiscal Decentralization and Deficits: International Evidence." European Journal of Political Economy 26, no. 2: $155-166$

. 2013. "Fiscal Decentralization, Fiscal Rules and Fiscal Discipline." Economics Letters 121, no. 3: 528-532.

Norris, E.; J. Martinez-Vazquez; and J. Noregaard. 2000. "Making Decentralization Work: The Case of Russia, Ukraine and Kazakstan.” Mimeograph.Washington, DC: IMF.

Oates, W.E. 1972. Fiscal Decentralization. New York: Harcourt Brace Jovanowich. .1999. “An Essay on Fiscal Federalism.” Journal of Economic Literature 37, no. 3: 1120-1149.

Panizza, U. 1999. "On the Determinants of Fiscal Centralization: Theory and Evidence.” Journal of Public Economics 74, no. 1: 97-139.

Sanguinetti, P., and M. Tomassi. 2004. "Intergovernmental Transfers and Fiscal Behaviour Insurance Versus Aggregate Discipline." Journal of International Economics 62, no. 1: 149-170.

Smoke, P.; E.J. Gomez; and G.E. Peterson (eds.). 2006. Decentralization in Asia and Latin America: Towards a Comparative Interdisciplanary Perspective. Cheltenham, UK: Edward Elgar.

Stowhase, S., and C. Traxler. 2005. "Tax Evasion and Auditing in a Federal Economy," International Tax and Public Finance 12, no. 4: $515-531$.

Tanzi, V. 2000. "On Fiscal Federalism: Issues to Worry About:” Working paper. Conference on Fiscal Decentralization, Fiscal Affairs Department. Washington DC: IMF.

Thiessen, U. 2003. "Fiscal Decentralization and Growth in High-Income OECD Countries.” Fiscal Studies 24, no. 3: 237-274.

Treisman, D. 2000. "Decentralization and the Quality of Government." Department of Political Science, University of California, Los Angeles. www.sscnet.ucla.edu/polisci/faculty/treisman/Decandgovt.pdf.

Von Braun, J., and U. Grote. 2000. "Does Decentralization Serve the Poor?" Center for Development Research, University of Bonn, Germany.

Von Hagen, J., and R. Hepp. 2000. "Regional Risk-sharing and Redistribution in the German Federation.” ZEI Working Paper no. B 15, University of Bonn, Germany

Wasylenko, M. 2001. "Fiscal Decentralization and Economic Development." Mimeograph, The Maxwell School, Syracuse, NY: Syracuse University.

Wolff, G.B. 2005. "Measuring Tax Burdens in Europe.” ZEI Working Paper 09-2005.

\section{Appendix 1}

\section{Optimal Choice of $\mathrm{p}$ and $\mathrm{m}$}

For the LG problem, it is essential to know how the central government will redistribute a common pool of revenues; i.e., the set of punishment and equalization parameters corresponding to each pair (since $n=2$ ) of potential effort levels pertaining to the localities. Hence, parameters $p$ and $m$ are determined optimally by the CG as a solution to the problem, where CG maximizes the sum of utilities of all localities subject to the condition that the total pool of revenues is equal to the total transfers that is now expressed via the redistributive rule

$$
\begin{gathered}
\max _{p, m} \sum_{i=1}^{n}\left(\alpha \ln C_{i \mid}+\beta \ln G_{i}\right) \\
\text { s.to } \quad c t \sum_{i=1}^{n} A_{i} Y_{i}=\sum_{i=1}^{n}\left(p t Y_{i}\left(A_{i}-1\right)+m\left(Y_{i}^{*}-Y_{i}\right)\right) .
\end{gathered}
$$

Optimal values of $p$ and $m$ are obtained as the solution to the above problem, given that the effort of each locality ranges between zero and one. The values of TR simulated for this problem are the same as the one obtained under the CG problem reported earlier due to the left-hand side of the constraint. 


\section{Appendix 2}

\section{Solutions of the CG and LG Problems}

\section{A2.1 Finding Optimal $\mathrm{p}$ and $\mathrm{m}$}

The problem of CG defined in Appendix 2 can be written (for $n=2$ ) as:

$$
\mathrm{L}=\sum_{i=1}^{2}\left(\alpha \ln C_{i \mid}+\beta \ln G_{i}\right)+\mu\left(c t \sum_{i=1}^{2} A_{i} Y_{i}-\sum_{i=1}^{2}\left(p t Y_{i}\left(A_{i}-1\right)+m\left(Y_{i}^{*}-Y_{i}\right)\right)\right)
$$

where $\mathrm{L}$ denotes the Lagrangean and $\mu$ is the Lagrange multiplier, yielding unique solutions for $p$ and $m$.

\section{A2.2 The LG Problem (Nonstrategic Case: FD)}

Substituting the transfer constraint (Equation 2) into the objective function (Equation 1) yields:

$$
\mathrm{L}=\alpha \ln \left(\left(1-t A_{i}\right) Y_{i}\right)+\beta \ln \left((1-c) t A_{i} Y_{i}+p t Y_{i}\left(A_{i}-1\right)+m\left(Y_{i}^{*}-Y_{i}\right)\right)
$$

The first order condition obtained from the solution of the above Lagrangean with respect to $A_{i}$, gives optimal tax effort as in Equation (3).

\section{A2.3 The LG Problem (Strategic Case: FD Nash)}

From the constraint of the $\mathrm{FD}^{\text {Nash }}$ problem (Equation 5), $A_{i}$ can be written in terms of the other agents' tax effort $\left(A_{j}\right)$. Because each LG assumes that the others select their optimal efforts in the same fashion, $j$ 's reaction function is also written in terms of $A_{i}$ and its substitution in (6) results in Equation (7).

\section{A2.4 The CG Problem}

Using Equation (5):

$$
T R_{j}=c t\left(A_{1} Y_{1}+A_{2} Y_{2}\right)-T R_{i}, i \neq j .
$$

The Lagrange of this maximization problem for each locality becomes:

$$
\begin{aligned}
\mathrm{L}= & \alpha \ln \left(\left(1-t A_{1}\right) Y_{1}\right)+\alpha \ln \left(\left(1-t A_{2}\right) Y_{2}\right)+\beta \ln \left((1-c) t A_{i} Y_{i}+T R_{i}\right) \\
& +\beta \ln \left((1-c) t A_{j} Y_{j}+c t\left(A_{1} Y_{1}+A_{2} Y_{2}\right)-T R_{i}\right)
\end{aligned}
$$

which yields the following first order condition with respect to $T R_{i}$ :

$$
T R_{i}=c t A_{i} Y_{i}+\frac{t A_{j} Y_{j}-t A_{i} Y_{i}}{2}
$$

\section{Appendix 3}

\section{Comparative Statics}

Comparative statics for the unambiguous results (for $i, j=1,2 ; 1$ is the poor region)

$$
\text { FD Problem : } \quad \partial A_{i} / \partial\left(Y_{i}^{*}-Y_{i}\right)<0 ; \partial T R_{i} / \partial\left(Y_{i}^{*}-Y_{i}\right)>0
$$

FD-NashProblem : $\partial A_{i}^{o} / \partial A^{0}{ }_{j}>0$, if $p>c$ 


\section{CG Problem : $\quad \partial T R / \partial c>0 ; \partial T R / \partial n>0 ; \partial T R / \partial t>0 ; \partial T R / \partial A_{i}>0 ; T R / \partial>0$.}

Simulation of the ambiguous comparative statics results - for the LG problem:

Nash Solution:

$$
\begin{gathered}
\partial A_{i}^{o} / \partial \alpha>0 ; \partial A_{1}^{o} / \partial \beta<0 ; \partial A_{2}^{o} / \partial \beta=0 ; \partial A^{0}{ }_{i} / \partial p>0 ; \partial A_{i}^{o} / \partial m<0 ; \\
\partial A_{i}^{o} / \partial c>0 ; \partial A_{i}^{o} / \partial t>0 ; \partial A_{i}^{o} / \partial A^{0}{ }_{j}>0(\text { for } p>c) ; \partial A_{i}^{o} / \partial\left(Y_{i}^{*}-Y_{i}\right)<0 ; \\
\partial T R_{i} / \partial A_{i}>0 ; \partial T R_{i} / \partial A_{j}<0 ; \partial T R / \partial A_{i}<0 .
\end{gathered}
$$

$\partial T R / \partial \alpha>0 ; \partial T R / \partial \beta<0 ; \partial T R / \partial c>0 ; \partial T R / \partial t>0 ; \partial T R / \partial m<0 ; \partial T R / \partial p>0 ; \partial T R / \partial\left(Y_{i}^{*}-Y_{i}\right)>0$.

The same results are obtained for individual transfers: $T R_{i}$, except for $\partial T R_{2} / \partial p$ which is indeterminate.

Non-Strategic Solution:

$$
\begin{gathered}
\partial A_{i}^{o} / \partial \alpha=? ; \partial A_{i}^{o} / \partial \beta=? ; \partial A_{i}^{o} / \partial p>0 ; \partial A_{i}^{o} / \partial m<0 ; \partial A_{i}^{o} / \partial c<0 ; \partial A_{i}^{o} / \partial t=? ; \\
\partial T R / \partial \alpha=? ; \partial T R / \partial \beta=? ; \partial T R / \partial c<0 ; \partial T R / \partial t=? ; \partial T R / \partial m>0 ; \partial T R / \partial p>0 \\
\partial T R_{i} / \partial A_{i}>0 ; \partial T R / \partial\left(Y_{i}^{*}-Y_{i}\right)>0
\end{gathered}
$$

\begin{tabular}{|c|c|c|c|c|c|c|c|c|c|}
\hline & $\alpha$ & $\boldsymbol{\beta}$ & $c$ & $m$ & $k$ & $t$ & $A_{1}$ & $A_{2}$ & $\left(Y_{i}^{*}-Y_{i}\right)$ \\
\hline \multicolumn{10}{|c|}{ LG PROBLEM: } \\
\hline \multicolumn{10}{|c|}{ Strategic Solution: } \\
\hline$A_{1}$ & + & - & + & - & + & + & na & + & - \\
\hline$A_{2}$ & + & - & + & - & + & + & + & na & - \\
\hline$T R_{1}$ & + & - & + & - & + & + & + & - & + \\
\hline$T R_{2}$ & + & - & + & - & $?$ & + & - & + & + \\
\hline$T R$ & + & - & + & - & + & + & - & - & + \\
\hline \multicolumn{10}{|c|}{ Non-Strategic Solution: } \\
\hline$A_{1}$ & $?$ & ? & - & - & + & $?$ & na & na & - \\
\hline$A_{2}$ & $?$ & ? & - & - & + & $?$ & na & na & - \\
\hline$T R_{1}$ & $?$ & ? & - & + & + & $?$ & + & + & + \\
\hline$T R_{2}$ & $?$ & $?$ & - & + & + & $?$ & + & + & + \\
\hline$T R$ & $?$ & ? & - & + & + & $?$ & + & + & + \\
\hline \multicolumn{10}{|c|}{ CG PROBLEM: } \\
\hline$T R$ & na & na & + & na & na & + & + & + & na \\
\hline$T R_{1}$ & na & na & + & na & na & na & na & na & na \\
\hline$T R_{2}$ & na & na & + & na & na & na & na & na & na \\
\hline
\end{tabular}

The same results are obtained for individual transfers: $T R_{i}$ These results are summarized in Table A1 (for $I=1,2$ ).

Table A1. Comparative statics of $T R, T R_{i}$, and $A_{i}$ 